\title{
Retrospective Analysis of Delayed Intraparenchymal Hemorrhage after Flow-Diverter Treatment: Presentation of a Retrospective Multicenter Trial
}

\author{
(D) A. Benaissa, (D) Tomas, (D)F. Clarençon, (D) N. Sourour, (DD. Herbreteau, (D). Spelle, (D). Gallas, (D)A.-C. Januel, (D)A.L. Gaultier, \\ and (DL. Pierot
}

\begin{abstract}
BACKGROUND AND PURPOSE: Intracranial aneurysm treatment with flow diverters has shown satisfying results in terms of aneurysm occlusion, and while some cases of delayed intraparenchymal hemorrhage have been described, no systematic analysis of the risk factors affecting its occurrence has been conducted in a large series of patients. This retrospective analysis of delayed intraparenchymal hemorrhage after flow-diverter treatment is a multicenter, retrospective study using a large series of treated patients to analyze factors affecting the occurrence of delayed intraparenchymal hemorrhage.
\end{abstract}

MATERIALS AND METHODS: Patients treated with flow diverters and presenting with delayed intraparenchymal hemorrhage were included from December 2007 to December 2014 in 7 participating centers in France. Patient and aneurysm characteristics were recorded as were characteristics of bleeding (size, lateralization, and time to bleed), treatment, and clinical outcome after 1, 3, and 6 months.

RESULTS: Delayed intraparenchymal hemorrhage occurred in 11 patients between 1 and 21 days after the procedure. In 10 of these patients, hemorrhages were ipsilateral to the treated aneurysms. Five of the 11 underwent surgery, and 9 of the 11 had good clinical outcomes at 6 months (mRS $\leq$ ).

CONCLUSIONS: The pathogenesis of delayed intraparenchymal hemorrhage occurring after flow-diverter treatment remains unclear. The multidisciplinary management of delayed intraparenchymal hemorrhage yields a relatively low morbidity-mortality rate compared with the initial clinical presentation.

ABBREVIATIONS: $\mathrm{FD}=$ flow diverter; $\mathrm{DIPH}=$ delayed intraparenchymal hemorrhage

D uring recent decades, endovascular treatment has become the first-line treatment for intracranial aneurysms. ${ }^{1-3}$ Nevertheless, treatment of giant, wide-neck, and fusiform aneurysms remains difficult and has evolved with the use of balloon- or stentassisted coiling, flow diverters (FDs), and flow disrupters. ${ }^{4}$ The use of FDs has shown promising results in the treatment of complex and recanalized aneurysms. ${ }^{5,6}$ However, thromboembolic complications and aneurysm rupture can occur during and after

\footnotetext{
Received May 28, 2015; accepted after revision July 29.

From the Department of Neuroradiology (A.B., C.T., L.P.), Centres Hospitaliers Universitaires de Reims, Reims, France; Department of Neuroradiology (F.C., N.S.), Centres Hospitaliers Universitaires of Pitié-Salpêtrière, Paris, France; Department of Neuroradiology (D.H.), Centres Hospitaliers Universitaires of Tours, Tours, France; Department of Neuroradiology (L.S.), Centres Hospitaliers Universitaires of Beaujon, Clichy, France; Department of Neuroradiology (S.G.), Centres Hospitaliers Universitaires of Créteil, Créteil, France; Department of Neuroradiology (A.-C.J.), Centres Hospitaliers Universitaires of Toulouse, Toulouse, France; and Department of Neuroradiology (A.L.G.), Centres Hospitaliers Universitaires of Nantes, Nantes, France.

Please address correspondence to Laurent Pierot, MD, Service de Neuroradiologie, Hopital Maison Blanche, 45, Rue Cognacq Jay, 51092 Reims Cedex, France; e-mail: Ipierot@chu-reims.fr

http://dx.doi.org/10.3174/ajnr.A4561
}

FD treatment. ${ }^{7-10}$ More recently, cases of delayed intraparenchymal hemorrhage (DIPH) have also been reported with potential serious worsening. ${ }^{11-15}$ To date, the clinical presentation, etiopathogeny, and management of this complication are not wellunderstood, and published series of DIPH cases have included a limited number of patients and did not analyze precisely aneurysm, procedural, and postprocedural factors that may affect the occurrence of such complications.

The aim of this retrospective study was to describe and analyze the clinical presentation, modalities of treatment, and outcomes in a series of 11 patients who presented with DIPH.

\section{MATERIALS AND METHODS \\ Patient Selection}

From 2007 to 2014, patients treated with a flow diverter and who presented with DIPH after treatment were retrospectively included from 7 French interventional neuroradiologic centers (Pitié-Salpétrière, Tours, Reims, Nantes, Créteil, Toulouse, and Beaujon). Because of the study design, informed consent was waived. Flow-diverter treatment was decided after a mul- 
tidisciplinary decision-making process. The study received institutional review board approval.

\section{Endovascular Procedure}

For all patients, the treatment was performed with the patient under general anesthesia by an experienced interventional neuroradiologist with at least 5 years' experience. The $3 \mathrm{D}$ reconstruction and 2D working projections were used to measure the parent artery, allowing selection of the FD size. A $6 \mathrm{~F}$ long sheath or a $6 \mathrm{~F}$ guiding catheter was used via transfemoral access. The precise type of introducer sheath and/or guiding catheter used during the procedure was not systematically registered in the procedure reports. A coaxial system catheter was used for stent navigation, with a guiding catheter (or sheath) in which a delivery microcatheter was inserted. A 0.027-inch inner diameter Marksman microcatheter (Covidien, Irvine, California) was used for the Pipeline Embolization Device (Covidien), a 0.040-inch inner diameter Surpass microcatheter (Stryker Neurovascular, Kalamazoo, Michigan) was used for the Surpass FD, and a 0.021-inch inner diameter Vasco +21 microcatheter (Balt Extrusion, Montmorency, France) was used for the Silk FD (Balt Extrusion). The FD was used to cover the aneurysm neck. The correct deployment was controlled by DSA and CT angiography.

One periprocedural complication was described (initial misdeployment of the FD that further opened spontaneously). No immediate postprocedural complications were observed. No perforation of a distal vessel or hemorrhagic or thromboembolic events were encountered.

\section{Short-Term and Midterm Clinical and Imaging Follow-Up} We reviewed the following characteristics of the DIPH: time to bleed, location, lateralization, size, associated lesions, clinical signs, and treatment. Clinical outcomes of each patient were evaluated according to mRS scores before FD treatment and at 1, 3, and 6 months. All patients underwent brain imaging during their hospital stay (CT or MR imaging).

\section{RESULTS}

\section{Population}

From 2007 to 2014, 449 patients were treated with FDs in the 7 participating French university centers. Among these, 11 (2.4\%) presented with DIPH after FD treatment and were retrospectively included. A precedent series including 4 of these 11 patients has already been published. ${ }^{14}$

The group consisted in 4 men and 7 women ranging in age from 30 to 61 years (mean, $46.1 \pm 9.9$ years; median, 46.0 years). Five had known histories of arterial hypertension, and 7 were smokers. All had mRS scores of zero before FD treatment. Nine aneurysms treated with FDs in these participating centers were unruptured.

Aneurysm Data. Nine aneurysms were situated in the ICA (3 cavernous ICAs and 6 supracavernous ICAs), and 2 were situated in the posterior cerebral circulation ( 1 basilar artery and 1 vertebral artery; Fig 1). Eight aneurysms were saccular, and 3 were fusiform. Four were small $(<10 \mathrm{~mm})$, and 7 were large or giant $(>10 \mathrm{~mm})$. The 8 saccular aneurysms ranged in size from 4.2 to $30 \mathrm{~mm}$ (mean, $12.4 \pm 7.7 \mathrm{~mm}$; median, $11 \mathrm{~mm}$ ), and the necks of the aneurysms ranged from 2.5 to $13 \mathrm{~mm}$. Three had already been treated with coils ( 2 patients) or coils and a stent ( 1 patient), and 2 were initially ruptured.

\section{Flow Diverters}

We used 3 types of FDs: Pipeline (Covidien), Surpass (Stryker Neurovascular), and Silk (Balt Extrusion). The 11 aneurysms were treated with 15 FDs ( 9 by using a single FD, 1 with 2 FDs, and 1 with 4 FDs). Among the 15 FDs used, 11 were Pipeline, 3 were Surpass, and 1 was Silk, used in 8,2 , and 1 patient, respectively.

\section{Antiplatelet Regimen}

Preprocedure. Six patients had a dual-antiplatelet regimen (clopidogrel and aspirin), and 5 had single clopidogrel therapies. Among the 6 patients with dual-antiplatelet therapy, aspirin was started 1-7 days before the procedure in variable doses. Clopidogrel was started 5-6 days before the procedure at $75 \mathrm{mg} /$ day in 9 patients. In the remaining 2 , clopidogrel was started 1 day before the procedure with a loading dose of $450 \mathrm{mg}$. The efficacy of the antiaggregation therapy was checked in 5 patients (Multiplate analyzer; Roche, Basel, Switzerland). Among these 5 patients, 4 had normal platelet function response. In the remaining patient, moderate resistance led to an increase in the clopidogrel dose.

Perprocedure. Periprocedural heparinization was used in all cases. Six patients had a loading dose of aspirin at the beginning of the procedure (including the 5 patients who had single antiplatelet treatment before the procedure and 1 patient who received dual-antiplatelet therapy before treatment).

Postprocedure. Dual-antiplatelet therapy (75 mg/day of clopidogrel and $160 \mathrm{mg} /$ day of aspirin) was continued postprocedurally. Postprocedural heparinization was maintained in 6 patients during the 24 hours following the procedure. The clinical status of all patients remained unchanged after the FD procedure. Three patients underwent CT after the procedure and showed no hemorrhagic complications. Two had MRI showing no immediate ischemic complications.

\section{Intraparenchymal Hemorrhage Characteristics}

DIPH occurred between 1 and 21 days (mean, $7.7 \pm 6.6$ days; median, 7 days) after FD treatment. Hemorrhage was revealed by hemiparesis in 6 patients, aphasia in 4 , headache in 2 , and visual acuity loss in 1 patient. All hemorrhages were anatomically remote from the treated aneurysm (Fig 1). In 10 patients, the hematomas were located in the same region and on the same side. In 1 patient, the hematoma was located in the left superficial temporal lobe after the treatment of a sacciform basilar artery aneurysm.

The average size of the greater length of the intraparenchymal hematomas was $50.5 \mathrm{~mm}$ (range, $17-90 \mathrm{~mm}$; median, $50 \pm$ $20.8 \mathrm{~mm}$ ). In 5 patients, the DIPH was associated with a subdural or extradural hematoma. In all the patients with DIPH, clopidogrel was stopped and aspirin was maintained $(75 \mathrm{mg} /$ day) to prevent FD thrombosis. Five patients underwent surgery after receiving platelet transfusion. 

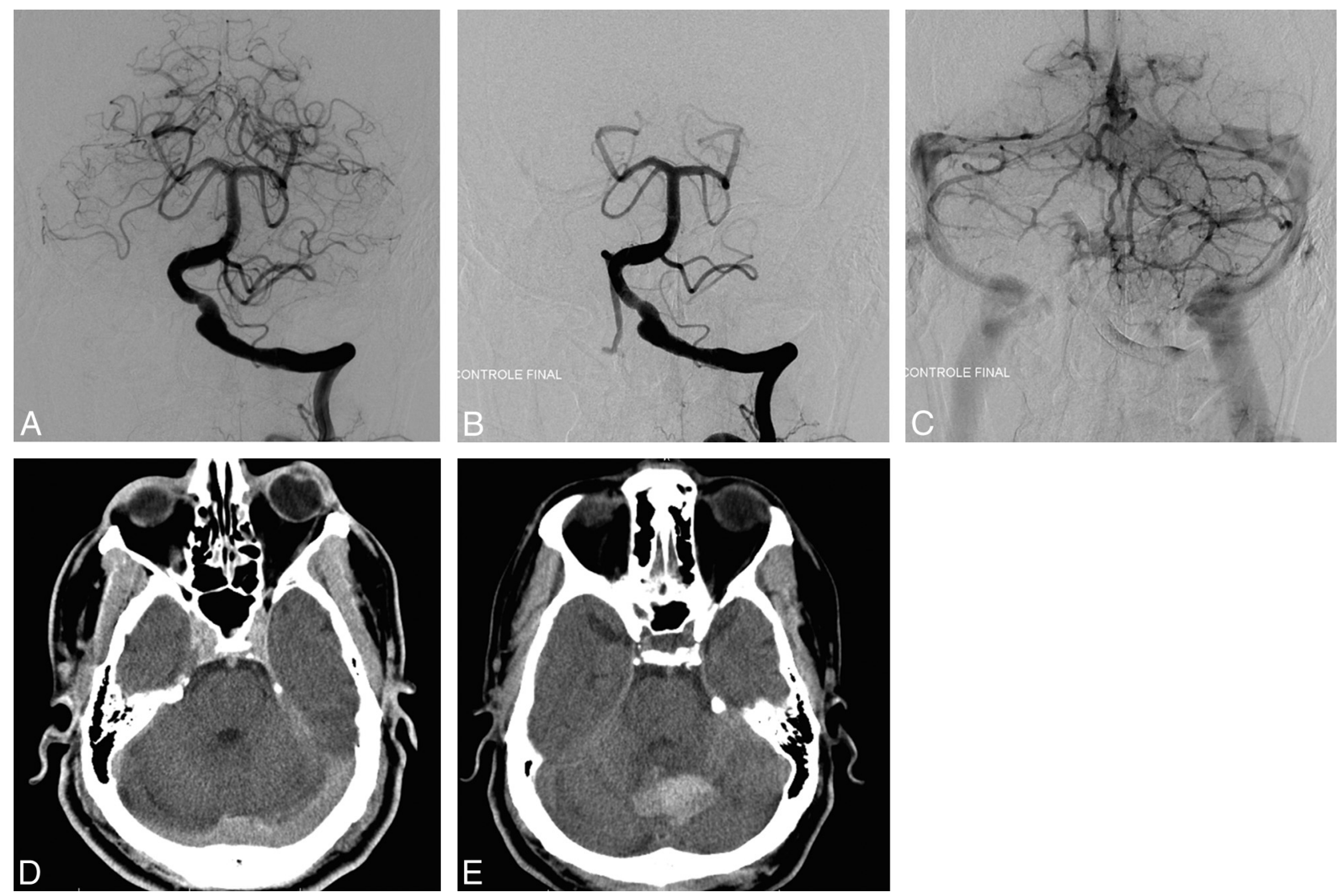

FIG 1. A, Pretreatment angiography shows a left vertebral fusiform aneurysm. $B$ and $C$, Postreatment angiography shows the placement and the permeability of the FD. D. Postreatment CT shows no postprocedural complications, mainly no intracranial bleeding. $E$, CT performed 7 days later for headache and aphasia reveals a vermian hematoma.

\section{Clinical Course}

Nine patients had good clinical outcomes at 6 months $(\mathrm{mRS} \leq 2)$. A severe disability remained in 1 patient ( $\mathrm{mRS} 5$ ) who had a right temporal voluminous hematoma treated by surgery. One patient died (mRS 6). Five were treated surgically by craniectomy and hematoma evacuation. Among them, 4 had good clinical outcomes at 6 months. The remaining patient had a severe disability (mRS 5). Among the 6 patients with conservative treatments, 5 had good clinical outcomes. The remaining patient died (mRS 6). In the 10 surviving patients, vascular imaging control performed at least 6 months after the procedure showed the FD to be patent.

\section{DISCUSSION}

To date, the occurrence of DIPH after FD treatment is a serious adverse event that appears unpredictable. In the literature, DIPH seems to be more frequent than delayed aneurysm rupture after the use of an FD. ${ }^{13,16}$ In our study, the frequency of DIPH was $2.4 \%$. Our findings are concordant with those in the literature, which reported a rate of DIPH between $1.1 \%$ and $8.5 \% .{ }^{11,13,14,16-18}$ In a recently published study including 793 patients with 906 aneurysms treated with the Pipeline Embolization Device, the rate of intracranial hemorrhage, not including aneurysm rupture, was $2.4 \%{ }^{19}$

In our study, DIPHs were revealed by headaches or focal neurologic deficit (hemiparesis, aphasia, or a decrease of visual acuity). The occurrence of DIPH seems to be independent of the preprocedural antiplatelet regimen or the type or number of FDs used for aneurysm treatment. The decision about whether and when to operate in cases of DIPH remains controversial. The surgical treatment of DIPH depends on the size and the location of the hematoma, the degree of mass effect, and the clinical presentation. Options available for neurosurgical treatment include hematoma evacuation and/or craniectomy, depending on the imaging features and on the neurosurgeon's habits. In our series, 5 patients were treated surgically, and all had craniectomies. In patients with severe clinical deterioration, elevated intracranial pressure, and/or mass effect seen on CT scans, hematoma evacuation is usually performed. The major advantages of craniectomy are adequate exposure for removal of the clot and prevention of complications such as hydrocephalus and mass effect of the blood clot. The major disadvantage is that it may lead to further brain damage. ${ }^{20}$ However, elevated intracranial pressure and poor cerebral perfusion pressure are associated with poor outcome, which, in these cases, supports a possible benefit from surgical intervention. Despite the International Surgical Trial in Intracerebral Hemorrhage results, craniectomy in intracerebral hemorrhage remains a matter of debate. ${ }^{21}$ Nevertheless, a recent small-sample-size study showed that decompressive craniectomy was possible in patients with intracerebral hematoma and it may reduce mortality. ${ }^{22}$ Prospective studies are needed to clarify the benefit of surgery in the treatment of intracerebral hematoma.

Because all patients treated with FDs have antiplatelet regimens, hemorrhagic complications resulting from surgical treat- 
ment may occur. Then, the neurosurgical treatment decision has to be made carefully. Before surgical treatment of DIPH, platelet transfusion and stopping clopidogrel appear logical, even if no consensus about the management of this complication is available. In our study, all of the patients who underwent an operation had platelet transfusion and stopped clopidogrel. Aspirin was maintained to prevent FD thrombosis.

\section{Etiology and Pathogenesis}

The cause of DIPH remains unclear and a matter of debate, but some hypotheses have been advocated to explain the occurrence of this complication. All hemorrhages found in this study were remote from the treated aneurysm, and most were located in the same region and on the same side. The location of these hemorrhages may be explained by the association of locoregional mechanisms, including flow modification, hemorrhagic transformation of ischemic lesions, or venous lesions. However, given that a single superficial temporal DIPH occurred after treatment of a posterior circulation aneurysm, the occurrence of DIPH may not be explained by only local or regional hypotheses. General mechanisms have to be taken into account, such as the antiplatelet regimen, to explain such hemorrhages. Therefore, DIPH is probably a consequence of the association of locoregional and general mechanisms.

\section{Inflammatory Reactions}

In a recent study, $\mathrm{Hu}$ et $\mathrm{al}^{15}$ performed postmortem analysis in 3 patients who had fatal DIPHs. Microscopic analyses revealed foreign material occluding the small arteries within the hemorrhagic area. The Fourier transform infrared spectroscopies showed that this material was polyvinylpyrrolidone, a substance used in the coating on a variety of interventional devices. No clinical ictus preceding death and no large vascular cerebral infarcts on the postmortem examination were observed. Thus, based on interventional cardiology literature, which described granulomas in the perivascular soft tissues after using polyvinylpyrrolidone, the potential role of the foreign body in the weakening and disruption of the arterial wall leading to vessel rupture and DIPH was suggested. However, neither granulomas nor inflammatory reactions were observed in the histologic analyses of these 3 patients.

$\mathrm{Hu}$ et $\mathrm{al}^{15}$ suggested that polyvinylpyrrolidone was coming from the introducer sheath used in the patients reported in this series. Unfortunately, the precise reference of introducer sheaths and guiding catheters used in the 7 participating centers was, in most cases, not reported in the procedure files, making analysis of the potential responsibility of polyvinylpyrrolidone in our cases impossible.

Systematic anatomic-pathologic analysis of the DIPH in surgically treated patients or postmortem analysis might confirm this hypothesis or help find an explanation for this type of complication. Unfortunately, no histopathologic analysis was performed in our cases.

Most interesting, a recent study reported 7 patients who developed MR imaging enhancing brain lesions after endovascular cerebral aneurysm treatment. These lesions were mostly in the vascular territory of the catheterized arteries, located in the corticosubcortical region where small emboli usually get lodged.
On the basis of the imaging and clinical characteristics, the authors suggested that these brain lesions might be the consequence of a foreign body reaction such as aseptic abscess and granulomas. These foreign bodies might be linked to dislodgment of the hydrophilic coating of the catheters used in endovascular treatment. ${ }^{23}$ However, no DIPH was observed in this series.

\section{Hemorrhagic Conversion of Ischemic Infarcts}

Occurrence of DIPH can be a consequence of hemorrhagic transformation of an ischemic lesion. Stroke can be the result of either thromboembolic events during the procedure or microemboli caused by foreign bodies. ${ }^{14,15,24}$ This mechanism may be a possible explanation for DIPH because 11 of 12 hemorrhages were ipsilateral to the treated aneurysm. However, no clinical symptom of an eventual cerebral stroke was described in our patients before hemorrhage occurred. Moreover, no ischemic lesion was observed on the postoperative MR imaging performed before bleeding in 2 patients in our series.

\section{Post-Flow Diversion Hyperperfusion Phenomenon}

Flow diverters permit the treatment of complex or giant intracranial aneurysms by using the concept of blood flow diversion, allowing the conservation of the parent artery and collateral vessels. Blood flow is modified not only in the aneurysm but also in the parent artery and side branches. ${ }^{10}$

Using FDs for the treatment of aneurysms changes the blood pressure waveform with a larger pulse pressure, which increases the pressure transmitted to the aneurysm and the distal cerebral arteries, leading to hemorrhagic complications. ${ }^{11}$

In their recent study, Gascou et $\mathrm{al}^{25}$ hypothesized that DIPH might be a result of hyperperfusion syndrome. This syndrome is related to a sudden increase in regional cerebral blood flow secondary to loss of cerebrovascular autoregulation. It has already been described after surgical treatment (clipping) and endovascular stent placement of intracranial aneurysms. ${ }^{26,27}$

Murakami et $\mathrm{al}^{28}$ suggested that giant aneurysms are responsible for the blood flow reduction in the parent artery. After FD treatment, the blood flow suddenly increases in the parent artery, increasing the pressure transmitted to the distal artery, exceeding cerebral autoregulation abilities and leading to cerebral hyperperfusion. This hyperperfusion could be a cause of intraparenchymal distal bleeding and then DIPH. However, in our series, DIPH occurred in 4 of 11 patients who had aneurysms with diameters of $<10 \mathrm{~mm}$, making this hypothesis less relevant.

\section{Antiplatelet Regimen, FD, and Stent}

Antiplatelet treatment is known to increase the risk of hemorrhagic events and to increase the size of intraparenchymal hematomas. ${ }^{29}$ Lately, antiplatelet treatment with hypertension has been associated with the occurrence of intracranial hemorrhages. ${ }^{29}$ Even if hemorrhagic complications occur after stent placement, their incidence is low, about 2.2\%; no intraparenchymal hemorrhage has been described remote from an aneurysm treated with stents. Therefore, the FD probably has a specific mechanism that may lead to intraparenchymal hemorrhage and that could be amplified by the antiplatelet regimen. Clopidogrel hyper-response or resistance is associated with hemorrhagic and 
thromboembolic complications, respectively, in patients treated with stents. ${ }^{30,31}$ The evaluation of the antiplatelet response may improve the clinical outcomes of patients treated with stents and FDs. Unfortunately, no consensus exists about the type of test or about how to use the results of these tests. Even if these tests were performed systematically before FD treatment, no consensual strategy of management is available on how to modify the preoperative antiplatelet regimen.

\section{Venous Lesion}

In their study, $\mathrm{Hu}$ et $\mathrm{al}^{15}$ also performed anatomic-pathologic analysis of the hematomas that showed attenuation of the tunica media of postcapillary venules with extravasated erythrocytes, suggesting a rise in the venule pressure and a potential venous mechanism in the occurrence of DIPH.

Cerebral venous thrombosis is a cause of parenchymal brain hemorrhage in both children and adults. ${ }^{32}$ Cerebral venous thrombosis is known to often be associated with an increase of the capillary pressure, which leads to cerebral edema, increased blood-brain barrier permeability, and hemorrhage. ${ }^{33}$ By modifying the postcapillary pressure, FD placement may also induce a higher venous pressure and then intraparenchymal hematoma. An FD-induced venous lesion (thrombosis or pressure modification) might be a potential explanation of hemorrhagic lesions in DIPH. Nevertheless such hemodynamic modifications were not clearly demonstrated, and FD placement has not been shown to modify venous pressure. This potential mechanism is probably the most difficult to demonstrate; thus, it is less relevant.

\section{Limitations of the Study}

First, our study included a small number of patients. However, the frequency of DIPH is low, and this study included a higher number of patients with DIPH. Second, because of its retrospective nature, our data remain subject to the biases of retrospective review. Third, because of the different heparinization procedures linked to a multicenter retrospective study, we did not discuss the impact of heparin therapy on the occurrence of DIPH. Fourth, this study analyzed the small subgroup of patients treated with FDs and presenting with DIPH. It is indeed not representative of the whole population in terms of periprocedural complications. Fifth, because our goal was to describe and analyze patients with DIPH, we have not analyzed the patients who are not known to have DIPH. Therefore patients lost to follow-up and potentially having a DIPH were not included, so the rate of DIPH is potentially underestimated.

Evaluation of the antiplatelet response was not performed in all patients included in the study because at the time of their treatment, all the participating centers did not include such evaluations in their routine management of FD treatment. Since 2014, evaluation of the antiplatelet response has been performed in most the centers.

\section{CONCLUSIONS}

Flow-diverting devices offer an alternative treatment for large and complex aneurysms. Nevertheless, DIPH seems to be an unexpected potential complication. The pathogenesis of this complication remains unclear, even though new hypotheses have emerged in the past few years. The multidisciplinary management of DIPH provides a relatively low morbidity-mortality rate compared with the initial clinical presentation.

Disclosures: Nader Sourour-UNRELATED: Consultancy: Covidien, Stryker. Laurent Spelle-UNRELATED: Consultancy: Sequent, Stryker, Medtronic; Payment for Lectures (including service on Speakers Bureaus): Sequent, Stryker, Medtronic; Travel/ Accommodations/Meeting Expenses Unrelated to Activities Listed: Sequent, Stryker, Medtronic. Laurent Pierot-UNRELATED: Consultancy: Codman, Covidien/ ev3, MicroVention, Neuravi, Sequent Medical.

\section{REFERENCES}

1. Molyneux A, Kerr R, Stratton I, et al; International Subarachnoid Aneurysm Trial (ISAT) Collaborative Group. International Subarachnoid Aneurysm Trial (ISAT) of neurosurgical clipping versus endovascular coiling in 2143 patients with ruptured intracranial aneurysms: a randomized trial. J Stroke Cerebrovasc 2002;11:304-14 CrossRef Medline

2. Pierot L, Spelle L, Vitry F, et al; ATENA investigators. Immediate anatomic results after the endovascular treatment of unruptured intracranial aneurysms: analysis of the ATENA series. AJNR Am J Neuroradiol 2010;31:140-44 CrossRef Medline

3. Pierot L, Cognard C, Ricolfi F, et al; CLARITY investigators. Midterm anatomic results after endovascular treatment of ruptured intracranial aneurysms with Guglielmi detachable coils and Matrix coils: analysis of the CLARITY series. AJNR Am J Neuroradiol 2012; 33:469-73 CrossRef Medline

4. Pierot L, Wakhloo AK. Endovascular treatment of intracranial aneurysms: current status. Stroke 2013;44:2046-54 CrossRef Medline

5. Chalouhi N, Tjoumakaris S, Starke RM, et al. Comparison of flow diversion and coiling in large unruptured intracranial saccular aneurysms. Stroke 2013;44:2150-54 CrossRef Medline

6. Benaissa A, Januel AC, Herbreteau D, et al. Endovascular treatment with flow diverters of recanalized and multitreated aneurysms initially treated by endovascular approach. J Neurointerv Surg 2015;7: 44-49 CrossRef Medline

7. Pierot L. Flow diverter stents in the treatment of intracranial aneurysms: where are we? J Neuroradiol 2011;38:40-46 CrossRef Medline

8. Mustafa W, Kadziolka K, Anxionnat R, et al. Direct carotid-cavernous fistula following intracavernous carotid aneurysm treatment with a flow-diverter stent: a case report. Interv Neuroradiol 2010;16: 447-50 Medline

9. Turowski B, Macht S, Kulcsár Z, et al. Early fatal hemorrhage after endovascular cerebral aneurysm treatment with a flow diverter (SILK-Stent): do we need to rethink our concepts? Neuroradiology 2011;53:37-41 CrossRef Medline

10. Cebral JR, Mut F, Raschi M, et al. Aneurysm rupture following treatment with flow-diverting stents: computational hemodynamics analysis of treatment. AJNR Am J Neuroradiol 2011;32:27-33 CrossRef Medline

11. Cruz JP, Chow M, O’Kelly C, et al. Delayed ipsilateral parenchymal hemorrhage following flow diversion for the treatment of anterior circulation aneurysms. AJNR Am J Neuroradiol 2012;33:603-08 CrossRef Medline

12. Kulcsár Z, Houdart E, Bonafé A, et al. Intra-aneurysmal thrombosis as a possible cause of delayed aneurysm rupture after flow-diversion treatment. AJNR Am J Neuroradiol 2011;32:20-25 CrossRef Medline

13. The ESMINT Retrospective Analysis of Delayed Aneurysm Ruptures after Flow Diversion (RADAR) study. http://www.ejmint.org/ original-article/1244000088. Accessed October 29, 2014

14. Tomas C, Benaissa A, Herbreteau D, et al. Delayed ipsilateral parenchymal hemorrhage following treatment of intracranial aneurysms with flow diverter. Neuroradiology 2014;56:155-61 CrossRef Medline

15. Hu YC, Deshmukh VR, Albuquerque FC, et al. Histopathological 
assessment of fatal ipsilateral intraparenchymal hemorrhages after the treatment of supraclinoid aneurysms with the Pipeline Embolization Device. J Neurosurg 2014;120:365-74 CrossRef Medline

16. Saatci I, Yavuz K, Ozer C, et al. Treatment of intracranial aneurysms using the Pipeline flow diverter embolization device: a single-center experience with long-term follow-up results. AJNR Am J Neuroradiol 2012;33:1436-46 CrossRef Medline

17. Becske T, Kallmes DF, Saatci I, et al. Pipeline for incoilable or failed aneurysms: results from a multicenter clinical trial. Radiology 2013; 267:858-68 CrossRef Medline

18. Fischer S, Vajda Z, Aguilar Perez M, et al. Pipeline embolization device (PED) for neurovascular reconstruction: initial experience in the treatment of $\mathbf{1 0 1}$ intracranial aneurysms and dissections. Neuroradiology 2012;54:369-82 CrossRef Medline

19. Kallmes DF, Hanel R, Lopes D, et al. International retrospective study of the Pipeline embolization device: a multicenter aneurysm treatment study. AJNR Am J Neuroradiol, 2015;36:108-15 CrossRef Medline

20. Broderick JP, Adams HP Jr, Barsan W, et al. Guidelines for the management of spontaneous intracerebral hemorrhage: a statement for healthcare professionals from a special writing group of the Stroke Council, American Heart Association. Stroke 1999;30:905-15 CrossRef Medline

21. Mendelow AD, Gregson BA, Fernandes HM, et al; STICH investigators. Early surgery versus initial conservative treatment in patients with spontaneous supratentorial intracerebral haematomas in the International Surgical Trial in Intracerebral Haemorrhage (STICH): a randomised trial. Lancet 2005;365:387-97 CrossRef Medline

22. Fung C, Murek M, Z'Graggen WJ, et al. Decompressive hemicraniectomy in patients with supratentorial intracerebral hemorrhage. Stroke 2012;43:3207-11 CrossRef Medline

23. Cruz JP, Marotta T, O’Kelly C, et al. Enhancing brain lesions after endovascular treatment of aneurysms. AJNR Am J Neuroradiol 2014; 35:1954-58 CrossRef Medline

24. Shannon P, Billbao JM, Marotta T, et al. Inadvertent foreign body embolization in diagnostic and therapeutic cerebral angiography. AJNR Am J Neuroradiol 2006;27:278-82 Medline

25. Gascou G, Lobotesis K, Brunel H, et al. Extra-aneurysmal flow modification following Pipeline embolization device implantation: focus on regional branches, perforators, and the parent vessel. AJNR Am J Neuroradiol 2015;36:725-31 CrossRef Medline

26. Kuroki K1, Taguchi H, Yukawa O. Hyperperfusion syndrome after clipping of an unruptured aneurysm: case report. Neurol Med Chir (Tokyo) 2006;46:248-50 Medline

27. Maruya J, Nishimaki K, Minakawa T. Hyperperfusion syndrome after neck clipping of a ruptured aneurysm on a dolichoectatic middle cerebral artery. J Stroke Cerebrovasc Dis 2011;20:260-63 CrossRef Medline

28. Murakami HI, Inaba M, Nakamura A, et al. Ipsilateral hyperperfusion after neck clipping of a giant internal carotid artery aneurysm: case report. J Neurosurg 2002;97:1233-36 CrossRef Medline

29. Toyoda K, Yasaka M, Iwade K, et al; Bleeding with Antithrombotic Therapy (BAT) Study Group. Dual antithrombotic therapy increases severe bleeding events in patients with stroke and cardiovascular disease: a prospective, multicenter, observational study. Stroke 2008;39:1740 - 45 CrossRef Medline

30. Fifi JT, Brockington C, Narang J, et al. Clopidogrel resistance is associated with thromboembolic complications in patients undergoing neurovascular stenting. AJNR Am J Neuroradiol 2013;34:716-20 CrossRef Medline

31. Comin J, Kallmes DF. Platelet-function testing in patients undergoing neurovascular procedures: caught between a rock and a hard place. AJNR Am J Neuroradiol 2013;34:730-34 CrossRef Medline

32. Huang AH, Robertson RL. Spontaneous superficial parenchymal and leptomeningeal hemorrhage in term neonates. AJNR Am J Neuroradiol 2004;25:469-75 Medline

33. Nagai M, Terao S, Yilmaz G, et al. Roles of inflammation and the activated protein $\mathrm{C}$ pathway in the brain edema associated with cerebral venous sinus thrombosis. Stroke 2010;41:147-52 CrossRef Medline 